\title{
A História da Cirurgia Torácica no Inca
}

\author{
History of Toracic Surgery at Inca
}

Edson Toscano Cunha' e Darcy da Silva Guimarães²

Com a criação do Centro de Cancerologia, instituído pelo Decreto Lei no 378 , de 13 de janeiro de 1937, foi dado início a luta contra o câncer no Brasil. 0 grupo pioneiro de médicos tratava 0 câncer com as três armas clássicas que existiam na época: bisturi, roentgentgerapia e curieterapia.

As lutas empreendidas por este grupo pioneiro, no sentido da sobrevivência e de um local condigno de trabalho, fazem parte da história do Instituto $\mathrm{N}$ acional de $\mathrm{C}$ âncer.

Do pequeno e bem montado Centro de Cancerologia, funcionando anexo ao $\mathrm{H}$ ospital Estácio de Sá, hoje Hospital da Polícia Militar do Rio de Janeiro, e depois transferido para o velho casarão localizado na rua C onde Laje no 54, na Lapa, graças à fibra e 0 entusiasmo dos pioneiros conseguiu manter-se vivo o espírito de luta e evoluir-se na criação de um órgão governamental de expressiva importância e atuação na área do câncer. Após muitas negociações com as autoridades e a criação do Serviço $N$ acional de Câncer, este instituído pelo D ecreto Lei 3.643/41, obteve-se a transferência de todas U nidades do órgão, para ocupar dependências do H ospital Gaffrée e Guinle.

0 volume de trabalho aumentava 0 prestígio e o bom nome que granjeava entre a sociedade e as demais instituições de saúde; profissionais eram atraídos pelas famosas mesas redondas; e, pouco a pouco, foi-se impondo a necessidade da especialização dentro da cancerologia.

A exemplo de outras seções criadas desde então, coube a um dos médicos pioneiros,
Egberto Penido Burnier, chefiar a Seção de Cirurgia do Tórax do Instituto de Câncer, criada em 1952. Contando com a colaboração dos médicos Ronald $\mathrm{N}$ yr Alonso da Costa e João M orisson M onteiro, foi implantada uma diferente mentalidade nessa nova Seção e o estadiamento dos tumores e suas indicações terapêuticas foram sistematizadas, melhorando igualmente as técnicas de diagnóstico e tratamento das lesões torácicas.

C om a oficialização da Seção de Cirurgia do Tórax através da aprovação do Regimento do Instituto $\mathrm{N}$ acional de $\mathrm{C}$ âncer, pelo $D$ ecreto no 50.251 , de 28 de janeiro de 1961, a mesma passou a ombrear-se com qualquer outro serviço na especialidade, tanto técnica quanto em aparelhagem. Foi quando se deu a incorporação do equipamento de broncoscopia rígida e a criação da Unidade de C inesioterapia, munida de moderna aparelhagem, observando-se, mais uma vez, um salto de qualidade no atendimentos dos doentes.

Posteriormente, outros membro foram agregados com a chegada dos médicos Euclair M iranda de Oliveira (cirurgiã) e Wolfgang George Lamprecht (que chegou a exercer a direção do IN CA entre 1978 e 1979) para 0 Setor de endoscopia respiratória. Para abranger todos os cuidados aos doentes com doenças do tórax, foi integrado ao grupo cirúrgico, o médico pneumologista Fernando M onastério Viruez, treinado no serviço do Professor $\mathrm{N}$ ewton Bethlem e, em insuficiência respiratória, com o Prof. Paul Sadoul, da Universidade de N ancy. 
A Seção manteve seu curso e, a partir de 1980, sob a chefia do médico cirurgião Ronald $\mathrm{N}$ yr Alonso da Costa e colaboração dos cirurgiões torácicos Fernando M onastério Viruez e Paulo de Biasi Cordeiro (integrado à equipe desde 1979), iniciou-se um grande processo de modernização e agregação de novos profissionais, propiciado pela Campanha Nacional de Combate ao Câncer. A partir de 1981, foram integrados a seção os cirurgiões torácicos Walter Roriz de Carvalho e M auro M usa Zamboni e a pneumologista Vera Luiza Costa e Silva (pneumologista que, a partir de 1987, dedicou-se ao combate ao tabagismo, ocupando diversos cargos no IN CA, com o que notabilizou-se nacional e internacionalmente, antes de transferir-se para a 0 rganização Mundial da Saúde, em 2000).

Em 1981, Ronald N yr Alonso da Costa assumiu a Chefia da Divisão de Cirurgia, sendo Walter Roriz de Carvalho nomeado para chefiar a Seção de Cirurgia do Tórax, o que o fez de 1981 a 1986. A Seção, então, começou sua reestruturação e aquisição de equipamentos de broncoscopia rígida com óticas telescópicas, fibrobroncóspio, toracoscópio, mediastinoscópio e de espirometria pulmonar computadorizada, aumentando consideravelmente o número de procedimentos de diagnóstico e tratamento nela realizados. Com a crescente demanda, a Seção de Cirurgia Torácica do IN CA agregou ao seu corpo médico, no final de 1981, o cirurgião torácico Edson Toscano Cunha.

Reuniões científicas conjuntas com os serviços de Radiodiagnóstico, Anatomia Patológica, O ncologia Clínica e Radioterapia, passaram a ser realizadas para estudo de casos clínicos, e também foi criado o Programa de Especialização em Cirurgia Torácica, em convênio com a Universidade Federal Fluminense. 0 primeiro especializando deste Programa foi o médico Emanuel Bastos Torquato, que passou a pertencer a equipe a partir de 1985, ano em que a pneumologista M aria Cristina Barbosa foi admitida na Seção.

Em 1986, Walter Roriz de Carval ho foi empossado Diretor do INCA e a Chefia da Seção de Cirurgia do Tórax passou a ser exercida por Paulo de Biasi Cordero, que a liderou de 1986 a 1995. N esse período, a Seção recebeu 0 cirurgião Samuel de Biasi e a pneumologista Cristina M aria G. Cantarino. Este grupo permaneceu inalterado até 1995, quando Paulo de Biasi Cordero passou a dirigir o $\mathrm{H}$ ospital do Câncer I do IN CA, passando a chefia da Seção de Cirurgia do Tórax a ser de responsabilidade de Edson Toscano Cunha. D esde então, foram acrescidos à Seção o médico Aureliano S. M otta Cavalcanti e, mais recentemente, a médica D eborah Cordero Lannes.

N os últimos 20 anos, a Seção de Cirurgia do Tórax do INCA vem mantendo um funcionamento regular, tanto do ponto devista assistencial, com a incorporação de várias técnicas e tecnologias (cirurgia vídeotoracoscópica, vídeo-broncoscopia e laser endoscópico, entre outros), como do ponto de vista científico, com produção de trabalhos, publicações em revistas nacionais e internacionais, elaboração de capítulos de livros e desenvolvimento de teses de mestrado e doutorado. M antém, ainda o Curso de Treinamento em Broncoscopia, o Curso de Especialização em Cirurgia Torácica Oncológica e o Curso Anual de Cirurgia Torácica O ncológica do IN CA.

Atualmente os integrantes da Seção de Cirurgia Torácica são os médicos Edson Toscano Cunha, Walter Roriz de Carvalho, Emanuel Bastos Torquato, Samuel de Biasi Cordeiro, Aureliano M otta Cavalcante, M auro M usa Zamboni, C ristina M aria G. Cantarino, D eborah Cordeiro Lannes e, atualmente respondendo pela direção do $\mathrm{H}$ ospital do Câncer I do IN CA, Paulo de Biasi Cordeiro.

Porém, a história da Seção de Seção de Cirurgia do Tórax, mais do que a história de uma Seção, e especialmente pelo número de dirigentes que já deu ao IN CA, é a história do próprio Instituto Nacional de Câncer. E dos diretores que 0 conduziram e 0 conduz: Mário K röeff (1938/I941), Alberto Lima de M oraes Coutinho (1941/1954), Luiz Carlos de Oliveira Júnior (1954/I956), Antônio Pinto Vieira (1956/ 1962), M oacyr Alves dos Santos Silva (I962/1963 el972/1974), Francisco Fialho (1963/1967 el969/ 1970), Jorge Sampaio de M arsillac M otta (1967/ 1969), U go de Castro Pinheiro G uimarães (1970/ 1972), Adayr Eiras de Araújo (I974/I978), João Carlos Cabral (1978), Wolfgang George Lamprecht (1978/1979), H iram Silveira Lucas (1979/1980), Ary Frauzino Pereira (1980/1985), Geraldo M atos de Sá (1985/1986), Walter Roriz de Carvalho (1986/1990), M arcos Fernando de O livera M oraes (1990/I998) e Jacob Kligerman (a partir de 1998). 